\title{
Determination of Saponification Value in Carnuba Wax by USP/NF Residual Titration Method <541>
}

\author{
Stephanie Turnbull, Lauren Bradshaw, Yusuf Yildiz \\ Centenary University Science Department, Hackettstown, NJ, USA \\ Email: *sayatoglu@yahoo.com
}

How to cite this paper: Turnbull, S., Bradshaw, L. and Yildiz, Y. (2019) Determination of Saponification Value in Carnuba Wax by USP/NF Residual Titration Method <541>. American Journal of Analytical Chemistry, 10, 423-427.

https://doi.org/10.4236/ajac.2019.109030

Received: August 2, 2019

Accepted: September 17, 2019

Published: September 20, 2019

Copyright $\odot 2019$ by author(s) and Scientific Research Publishing Inc. This work is licensed under the Creative Commons Attribution International License (CC BY 4.0).

http://creativecommons.org/licenses/by/4.0/

\section{Open Access}

\begin{abstract}
Saponification value is defined as $\mathrm{mg} \mathrm{KOH}$ needed to neutralize free acids and saponify esters in $1 \mathrm{~g}$ of the test substance. A search of the literature showed that the standard saponification methods of the U.S. Pharmacopeia, alcoholic potassium hydroxide were the only saponification reagent. The sample to investigate is saponified with an excess of ethanolic potassium hydroxide solution. After finished saponification the remaining excess of potassium hydroxide is determined by residual titration under Titrimetry $<541>$, with aqueous volumetric hydrochloric acid. In this study, a test for saponification value has been successfully determined in carnuba wax. The average result has been found $90.9 \mathrm{mg} \mathrm{KOH} / \mathrm{g}$ substance and, \% RPD was $1.65 \%$. This is in contradistinction to the U.S. Pharmacopeia/National Formulary (USP/ NF) Method.
\end{abstract}

\section{Keywords}

Saponification Value, Carnuba (Cera Carnuba) Wax, United States

Pharmacopeia

\section{Introduction}

The word wax comes from the Old English weax meaning "material of the honeycomb" carnuba wax. Copernica Cerifera Wax, also called Carnuba Wax, is obtained the leaves of the Brazilian tropical palm tree Copernica [1]. Copernica cerifera, and Rhus Succedanea Fruit Wax, also called Japan wax, is obtained from the berries of the sumac Rhus succedanea, which grows in Japan and Chine. Carnuba wax is the hardest of the commercial vegetable waxes. It is tough, amorphous, iustrous wax that varies in color from dirty yellow to brown, 
green or white. Japan wax is a tough malleable, sticky substance. There is no formula for carnuba wax [2]. Carnuba Wax consists chiefly of myricyl cerotate and small quantities of free cerotic acid and myricyl alcohol. A major component of carnuba wax coating on the leaves of Brazilian Palm and formula is $\mathrm{CH}_{3}\left(\mathrm{CH}_{2}\right)_{30} \mathrm{COO}\left(\mathrm{CH}_{2}\right)_{23} \mathrm{CH}_{3}$ [3].

Carnuba Wax is moderately coarse powder or flaxes, possessing a characteristic bland odor, and free from rancidity. Specific gravity is about 0.99. Insoluble in water, free soluble in warm benzene; soluble in warm chloroform and in warm toluene; slightly soluble in boiling alcohol [4].

A complex mixture of several chemical compounds, predominantly esters, aliphatic esters (strait-chain acids with even-numbered carbon chains from $\mathrm{C}_{30}$ to $\mathrm{C}_{34}$, Alpha-hydroxy esters (straight-chain hydroxyl acids) with even-numbered carbon chains from $\mathrm{C}_{22}$ to $\mathrm{C}_{28}$, straight-chain acids with even-numbered chains from $\mathrm{C}_{24}$ to $\mathrm{C}_{28}$, straight-chain monohyric alcohols and dihydric alcohols with even-numbered carbon chains from $\mathrm{C}_{24}$ to $\mathrm{C}_{34}$, cinnamic aliphatic diesters ( $\mathrm{p}$ methoxy cinnamic acids and dihydric alcohols) with even-numbered carbon chains from $\mathrm{C}_{24}$ to $\mathrm{C}_{34}$ also contain free acids, free alcohols, hydrocarbons and resins.

In this study, a test for saponification value has been successfully determined in carnuba wax. This is in contradistinction to the U.S. Pharmacopeia/National Formulary (USP/NF) Method.

Carnuba wax is used in the pharmaceutical industry for tablet coatings and binding. Carnuba wax primarily consists of fatty acid esters. Coating tablets with the wax enables easier swallowing of the tablet. Carnuba wax has many other uses, including uses from car wax to dental floss. Carnuba wax is a safe, non-toxic and inert ingredient [5] [6].

Carnuba wax is widely used in cosmetics, certain foods, and pharmaceutical formulations. Cosmetically, carnuba wax is commonly used in lip balms [7].

Carnuba wax is the hardest and highest-melting of the waxes commonly used in pharmaceutical formulations and is used primarily as a $10 \% \mathrm{w} / \mathrm{v}$ aqueous emulsion to polish sugar-coated tablets. Aqueous emulsions may be prepared by mixing carnuba wax with an ethanolamine compound and oleic acid.

Carnuba wax $(10 \%-50 \% \mathrm{w} / \mathrm{w})$ is also used alone or with other excipients such as hypromellose, hydroxypropyl cellulose, alginate/pectin-gelatin, Eudragit, and stearyl alcohol to produce sustained-release solid-dosage formulations [8]-[15].

\section{Materials}

\subsection{Equipment}

Burettes;

Analytical balance, having a sensitivity of $0.1 \mathrm{mg}$;

Graduated cylinder, $50 \mathrm{~mL}$;

Volumetric flasks;

Volumetric pipettes, $50 \mathrm{~mL}$; 
Electric hot plate and reflux condenser;

Round bottom flask, 3 arm (24/40) 250 mL, preferably of Pyrex;

$250^{\circ} \mathrm{C}$ thermometer in one-hole rubber stopper wrapped in Teflon type;

Cargille boiling chips;

Glass stirring rod.

\subsection{Chemicals}

Carnuba (Cera carnuba) pale yellow wax;

Ethyl alcohol, (Pharmco-Aaper, 95\%, HPLC Grade);

Purified water: Water was purified with a Milli Q System (Millipore, Milford, MA). Hydrochloric acid, concentrated, Pharmco-Aaper, 36.6\% - 38.0\%.

\section{Solutions}

Alcoholic potassium hydroxide $\mathrm{KOH}, 0.5 \mathrm{M}$ Volumetric Solution (VS) is prepared $17.0 \mathrm{~g}$ of $\mathrm{KOH}$ in $500 \mathrm{~mL} 96 \%$ ethyl alcohol.

Aqueous hydrochloric acid, 0.5 M Volumetric Solution (VS): Prepared by diluting $40 \mathrm{~mL}$ of concentrated $\mathrm{HCl}$ to $1 \mathrm{~L}$ with deionized water. Standardized vs $\mathrm{Na}_{2} \mathrm{CO}_{3}$.

Ethanol, neutralized against phenolphthalein.

Phenolphthalein Test Solution (TS).

\section{Procedure}

Place 1.5 - $2.0 \mathrm{~g}$ of the carnuba wax substance in a tared, 250-mL flask, weigh accurately. Prepare and conduct blank determinations simultaneously with the sample. Add to it $25.0 \mathrm{~mL}$ of $0.5 \mathrm{~N}$ alcoholic potassium hydroxide. Connect the air condenser and boil gently, but steadily, until saponified. This reflux usually requires about $30 \mathrm{~min}$, frequently rotating the content. Reflux time can be up to $90 \mathrm{~min}$ to ensure complete saponification, depending on the type of ester to be tested.

After the flask and condenser have cooled somewhat, but not sufficiently to form a jell, wash down the inside of the condenser with a small quantity of distilled water. Disconnect the condenser, add about $1 \mathrm{~mL}$ of phenolphthalein indicator and titrate with $0.5 \mathrm{~N} \mathrm{HCl}$ until the pink color just disappears. Record the volume of $0.5 \mathrm{~N}$ HCL required for the titration. The end point is very easily distinguished, of carnuba wax when this method was used. Perform a blank determination under the same conditions Titrimetry $<541>$, Residual Titrations [4].

Calculate the Saponification Value:

$$
\text { Result }=\left[M w \times\left(V_{B}-V_{T}\right) \times N\right] / W
$$

$M w=$ molecular weight of potassium hydroxide, 56.11;

$V_{B}=$ volume of $0.5 \mathrm{~N}$ hydrochloric acid consumed in the blank test $(\mathrm{mL})$;

$V_{T}=$ volume of $0.5 \mathrm{~N}$ hydrochloric acid consumed in the actual test $(\mathrm{mL})$; 
$N=$ exact normality of the hydrochloric acid;

$W=$ weight of the substance taken for the test $(\mathrm{g})$.

If the oil has been saturated with carbon dioxide for the purpose of preservation, expose it in a shallow dish in a vacuum desiccator for $24 \mathrm{~h}$ before weighing the test specimen [4].

\section{Result and Discussion}

The chemical properties of waxes are amongst the most important properties that determine the present condition of the wax. When heating the yellow carnuba wax with alcoholic potassium hydroxide volumetric solution, $0.5 \mathrm{~N}$, solution turns from clear to straw to brown tea color. With excessive heating (i.e. $235^{\circ} \mathrm{C}$ for $30 \mathrm{~min}$ ), solution turns black coffee color, but then too much $\mathrm{KOH}$ is consumed, with the result that the saponification value exceeds the acceptable range of 78 - $95 \mathrm{mg} \mathrm{KOH} / \mathrm{g}$ sample. Solution was completely clear at $185^{\circ} \mathrm{C}$, indicating that all wax sample has been saponified. Addition of water to cooled sample results in acidified soap, and with stirring resembles coffee with cream because of the color. The blank, on the other hand, remains clear even upon addition of water. A characteristic smell (like Murphy furniture soap) accompanies the solution after heating to $185^{\circ} \mathrm{C}$, both for sample and for blank, which in indicates a component of the ethanoic $\mathrm{KOH}$ and carnuba wax are responsible for the smell and for the color.

Notes: [Caution]: Potassium hydroxide, like all alkalies, can burn skin, eyes, respiratory tract severely. Wear heavy rubber gloves. Alkalies are extremely exothermic when mixed with water. Ethyl alcohol is flammable. Use fume hood when heating or evaporation this solvent. Substract the total determination reading from the blank reading and calculate the saponification value.

\section{Conclusion}

In this study, a test for saponification value has been successfully determined in carnuba wax.

The results obtained from $\mathrm{mg} \mathrm{KOH} / \mathrm{g}$ content of yellow carnuba wax. Expected saponification value for yellow carnuba wax is between 78 and $95 \mathrm{mg}$ $\mathrm{KOH} / \mathrm{g}$ sample. The saponification value has been found $90.1 \mathrm{mg} \mathrm{KOH} / \mathrm{g}$ for sample $\mathrm{A}$, and $91.6 \mathrm{mg} \mathrm{KOH} / \mathrm{g}$ sample for the sample $\mathrm{B}$ as duplicate). In Table $1, \% \mathrm{RPD}$ is $1.65 \%$ and the result meets the saponification.

Table 1. Result for Saponification value.

\begin{tabular}{ccccccc}
\hline & $\begin{array}{c}\text { Sample } \\
\text { Weight }(\mathrm{g})\end{array}$ & $\begin{array}{c}\mathrm{N} \text { of } \\
\mathrm{HCl}\end{array}$ & $\begin{array}{c}\text { Volume of } \\
\text { Titrant }(\mathrm{mL})\end{array}$ & $\begin{array}{c}\text { Sap. Value } \\
\mathrm{mg} \mathrm{KOH} / \mathrm{g}\end{array}$ & $\begin{array}{c}\text { Average } \\
\mathrm{mg} \mathrm{KOH} / \mathrm{g}\end{array}$ & $\begin{array}{c}\text { Conforms } \\
\text { Y/N }\end{array}$ \\
\hline Blank & 0.0000 & 0.5169 & 25.3 & 0.00 & $90.1+91.6$ \\
Sample A & 1.4485 & 0.5169 & 20.8 & 90.1 & 90.9 & Yes \\
Sample B Duplicate & 1.5508 & 0.5169 & 20.4 & 91.6 & \\
\hline
\end{tabular}




\section{Acknowledgements}

The authors are thankful to Dr. Krassi Lazarova, Head of the Science Department of the Centenary University to give us the opportunity to complete this research work.

\section{Conflicts of Interest}

The authors declare no conflicts of interest regarding the publication of this paper.

\section{References}

[1] Japanese Pharmacopeia (JP) (2008) Official Monographs, Carnuba Wax.

[2] Yildiz, Y. and Dasgupta, M. (2016) Unsaponifiable Matter in Carnuba Wax (Cera Carnuba) Wax, a Modification of the USP/NF and FCC Methods. American Journal of Analytical Chemistry, 7, 611-616. https://doi.org/10.4236/ajac.2016.78056

[3] Bruice, P.Y. (1998) Organic Chemistry, Second Edition. University of California, Santa Barbara. Prentice Hall, Upper Saddle River.

[4] Unites State Pharmacopeia/National Formulary (USP/NF). 41 Official Monographs $<541>$ Fats and Oils, Carnuba Wax.

[5] Dave, R.H. (2008) Overview of Pharmaceutical Excipients Used in Tablets and Capsules. Drug Topics (Online).

[6] Wolfmeier, U., Schmidt, H., Heinrichs, F.L., et al. (2000) Waxes. In: Ullmann's Encyclopedia of Industrial Chemistry, Wiley, Hoboken. https://doi.org/10.1002/14356007.a28_103

[7] Marti-Mestres, G., et al. (1999) Texture and Sensory Analysis in Stick Formulations. S.T.P. Pharma Sciences, 9, 371-375.

[8] Reza, M.S., et al. (2003) Comparative Evaluation of Plastic, Hydrophobic and Hydrophilic Polymers as Matrices for Controlled-Release Drug Delivery. Journal of Pharmaceutical Sciences, 6, 282-291.

[9] Gioannola, L.I., et al. (1995) Carnuba Wax Microspheres Loaded with Valproic Acid: Preparation and Evaluation of Drug Release. Drug Development and Industrial Pharmacy, 21, 1563-1572. https://doi.org/10.3109/03639049509069246

[10] Miyagawa, Y., et al. (1996) Controlled-Release of Diclofenac Sodium from Wax Matrix Granule. International Journal of Pharmaceutics, 138, 215-224. https://doi.org/10.1016/0378-5173(96)04547-4

[11] Aritomi, H., Yamasaki, Y., Yamada, K., Honda, H. and Koishi, M. (1996) Development of Sustained-Release Formulation of Chlorpheniramine Maleate Using Powder-Coated Micro Sponge Prepared by Dry Impact Blending Method. Yakuzaigaku, 56, 49-56.

[12] Huang, H.P., Mehta, S.C., Radebaugh, G.W. and Fawzi, M.B. (1994) Mechanism of Drug Release from an Acrylic Polymer Wax Matrix Tablet. Journal of Pharmaceutical Sciences, 83, 795-797. https://doi.org/10.1002/jps.2600830607

[13] Joseph, I. and Venkataram, S. (1995) Indomethacin Sustained Release from Alginate-Gelatin or Pectingelatin Coacervates. International Journal of Pharmaceutics, 126, 161-168. https://doi.org/10.1016/0378-5173(95)00173-5

[14] Kumar, K., et al. (1975) Sustained Release Tablet Formulation of Diethylcarbamazine Citrate (Hetrazan). International Journal of Pharmaceutics, 37, 57-59.

[15] Dave, S.C., et al. (1974) Sustained Release Tablet Formulation of Diphenhydramine Hydrochloride (Benadryl). Part II. Indian Journal of Pharmacology, 36, 94-96. 